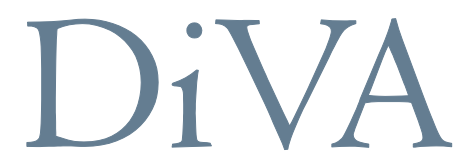

http://uu.diva-portal.org

This is the published version a paper presented at the Society of Exploration Geophysicists (SEG) Annual Meeting, 18-23 September 2011, San Antonio, Texas, USA.

Citation for the published paper:

Garcia Juanatey, M. et al.

"Integrated MagnetoTelluric and Seismic Reflection Study: Skellefte Ore District, Northern Sweden"

In: SEG Technical Program Expanded Abstracts, 2011, pp. 1247-1251. ISSN: $1052-3812$

URL: http://dx.doi.org/10.1190/1.3627429

Access to the published version may require subscription. 


\section{Integrated MagnetoTelluric and Seismic Reflection study: Skellefte Ore District, northern Sweden.}

María de los Ángeles García Juanatey*, Juliane Hübert, Christopher Juhlin, Alireza Malehmir, Ari

Tryggvason, Uppsala University

\section{Introduction}

The Skellefte District is a very rich mining area in northern Sweden. The main deposits consist of volcanic-hosted massive sulphides (VHMS) rich in zinc, copper, lead, gold and silver. Since the area has been mined and explored for over a century, today's challenge is to locate deeper deposits. The VINNOVA 4D modeling project aims to address this challenge by understanding the regional setting of the district and its evolution over time.

It is in the framework of this project that new geophysical and geological data have been acquired in the western part of the district. Figure 1 shows the seismic reflection lines and the locations of the MagnetoTelluric (MT) stations.

In this study we will focus on the outcomes from the northern profile (inside the rectangle in Figure 1). It is a continuation of a previous study in the Kristineberg area (Tryggvason et al. 2006, Malehmir et al. 2009, Hübert et al. 2009) towards the mineralizations in Adak. The main objectives of the study are the thickness of the Revsund granites and the structures below them.

The main geological units in the Skellefte District are the ore bearing rhyolitic volcanic rocks of the Skellefte Group; early granitoid intrusions coeval with the Skellefte Group that are considered as a possible heat source for hydrothermal fluids; sedimentary rocks of the Vargfors Group; felsic to intermediate volcanic rocks and late granitoid intrusions known as the Revsund granites. All these units are metamorphosed to greenschist and lower amphibolite facies.

\section{Data acquisition}

Figure 2 shows the location of the 17 broadband MT stations installed along the seismic reflection profile. Some of the stations were off the profile to avoid noise sources (e.g. power lines). All five (Ex, Ey, Hx, Hy, Hz) MT channels were recorded for all sites. The periods of the obtained transfer functions are between 0.002 and $200 \mathrm{~s}$.

The extent of the seismic reflection survey is shown in Figure 2 and the general acquisition parameters are listed int Table 1. For logistical reasons the acquisition line is crooked.

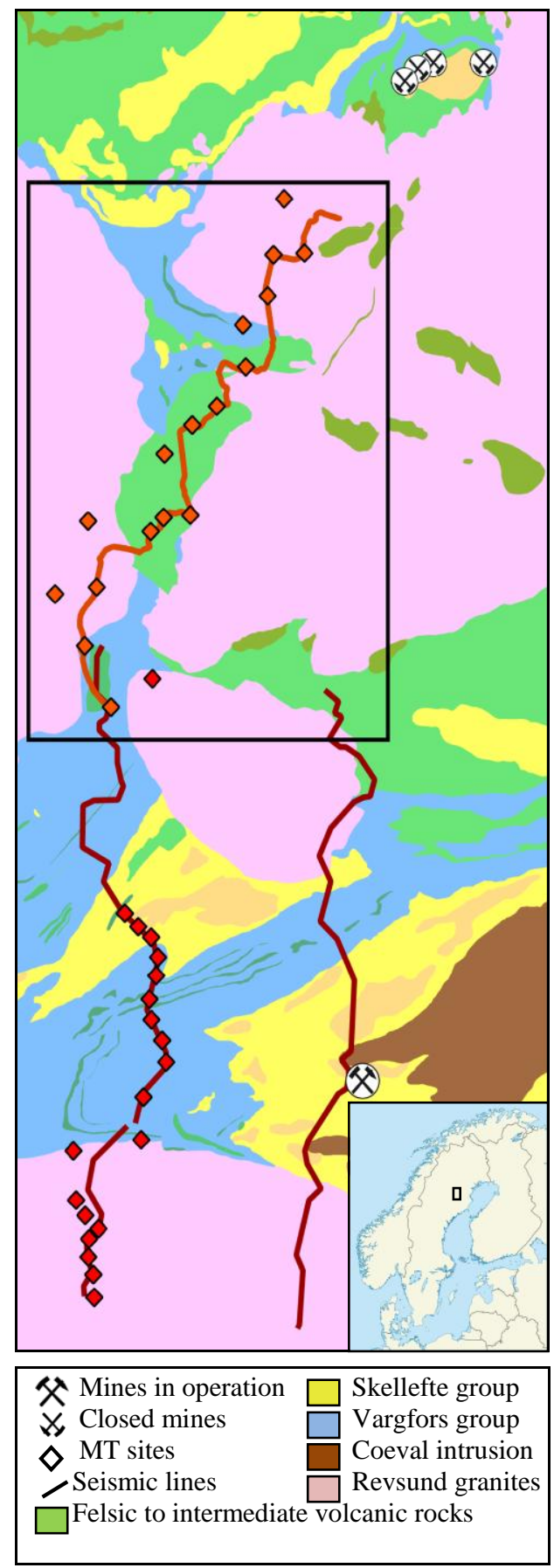

Figure 1. Geological map of the western part of the Skellefte District showing recently acquired geophysical data. 


\section{Integrated MagnetoTelluric and Seismic Reflection study}

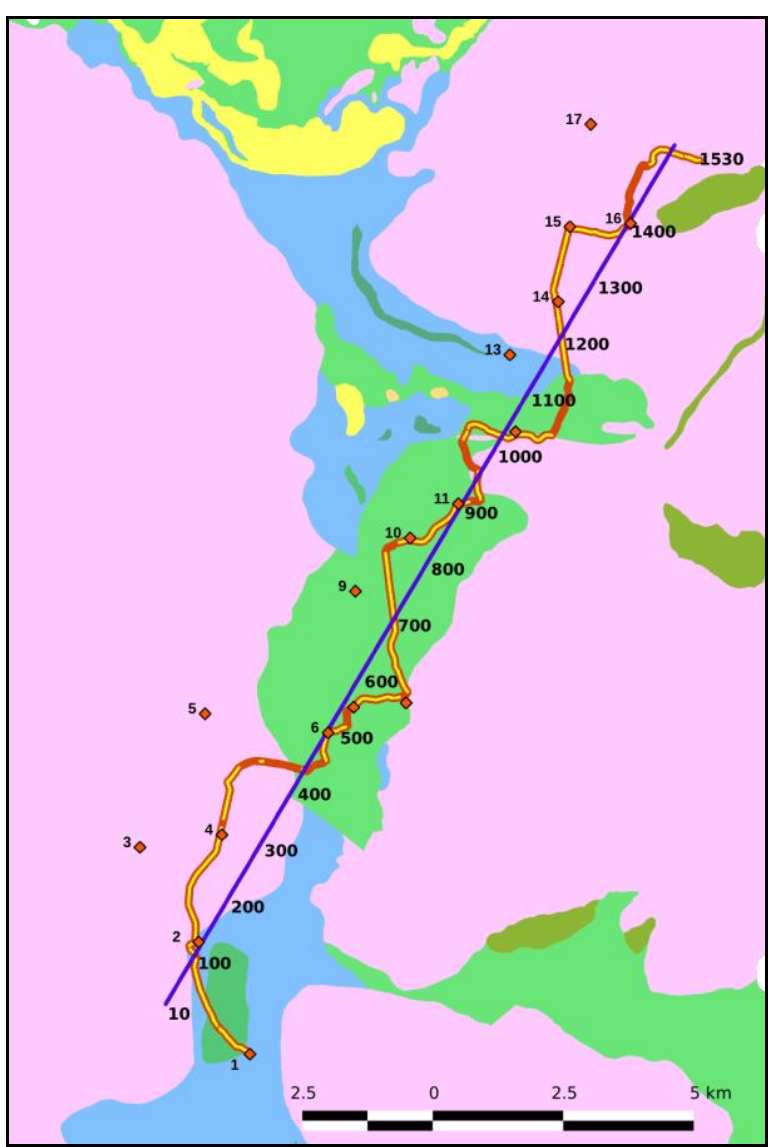

Figure 2. MT stations (diamonds) and seismic reflection acquisition line. The receiver locations are in red with the shot points in yellow on top. The CDP line is shown in blue with CDP numbers indicated to the right.

Table 1. Seismic reflection acquisition parameters.

$\begin{array}{ll}\text { Recording system } & \text { SERCEL } 408 \\ \text { Source type } & \text { VIBSIST } \\ \text { Shot spacing } & 25 \mathrm{~m} \text { (with gaps) } \\ \text { Receiver spacing } & 25 \mathrm{~m} \\ \text { Active channels } & 240-300 \\ \text { Number of sweeps } & 2-4 \\ \text { Sampling rate } & 1 \mathrm{~ms} \\ \text { Geophones } & \text { Single }(28 \mathrm{~Hz}) \\ \text { Total length } & 27 \mathrm{~km}\end{array}$




\section{Integrated MagnetoTelluric and Seismic Reflection study}

sets correlate and also where they contrast to one another. For example, the base of the resistor to the southwest coincides with $b$ or part of $a$. Reflectors $d$ and $e$ seem to bound the upper part of the dome-like zone of intermediate resistivity below the resistors between sites 11 and 15 . In contrasts, reflectors $a$ and $d$ seem to be minor structures in the resistivity model.

\section{Conclusions}

A stable 2D inversion model of the MT determinant data was obtained. Its most prominent features can be correlated with previous studies in the area and several reflections from the stacked seismic section. The deep conductor is found at $12 \mathrm{~km}$ depth and resistors show good correlation with the location of the Revsund granites. Overall, shallow resistivity structures show a good agreement with the surface geology. Nevertheless, as shown by the induction arrows the data set is not completely $2 \mathrm{D}$ and the obtained model may contain spurious or off-profile features. Therefore, a proper assessment of the resolution properties of the model is necessary.
Even though more work is required to fully exploit the two studied data sets, it is already possible to show the power of combining two independent methods to unravel subsurface structures. We believe that the combination of several methods and the interactive update of results is the key to success in the search for a common geological model.

\section{Acknowledgments}

This study was carried out within the VINNOVA 4D modeling project and with funding from the Geological Survey of Sweden.

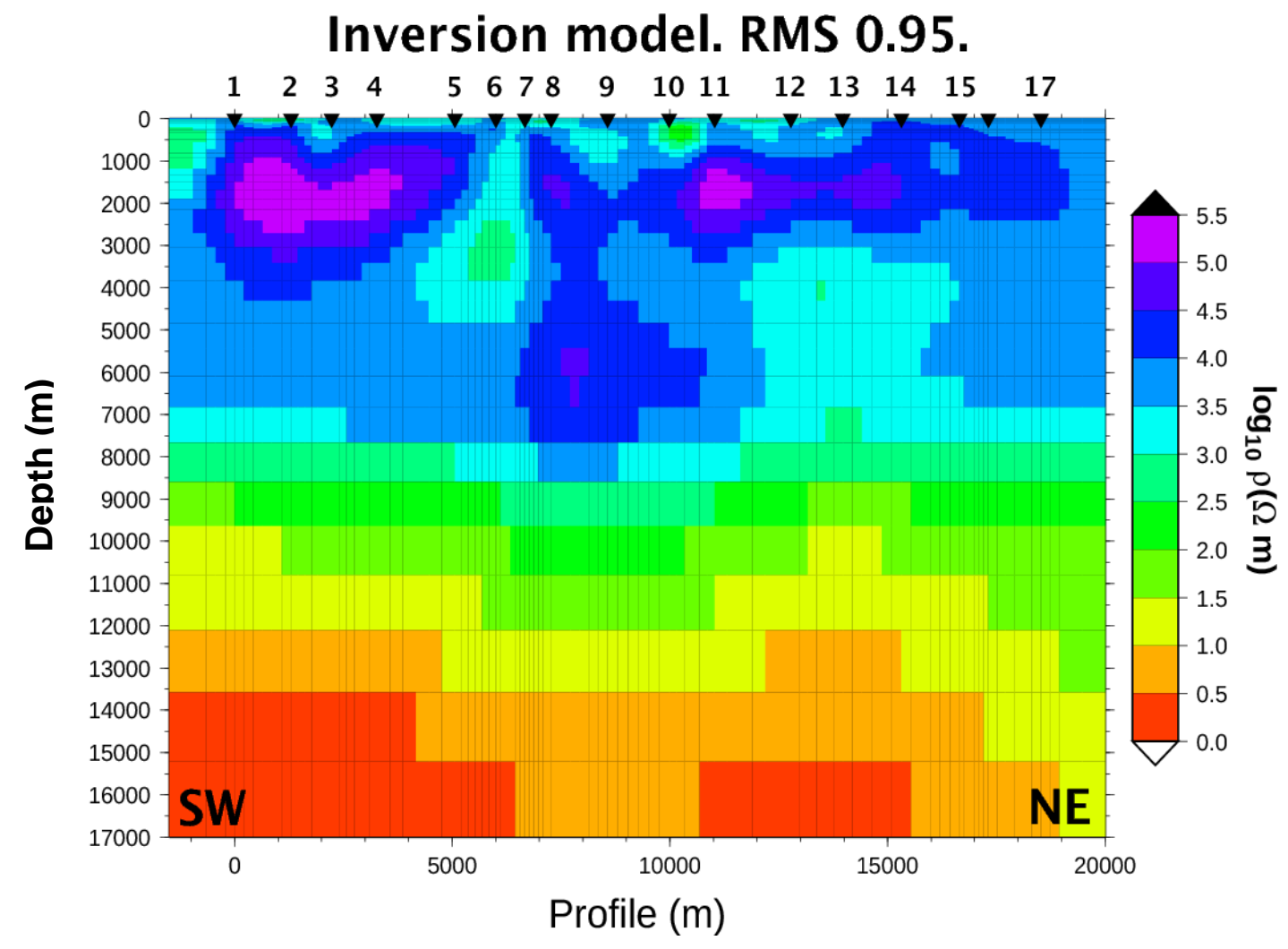

Figure 3. Inversion model for MT data. 


\section{Integrated MagnetoTelluric and Seismic Reflection study}

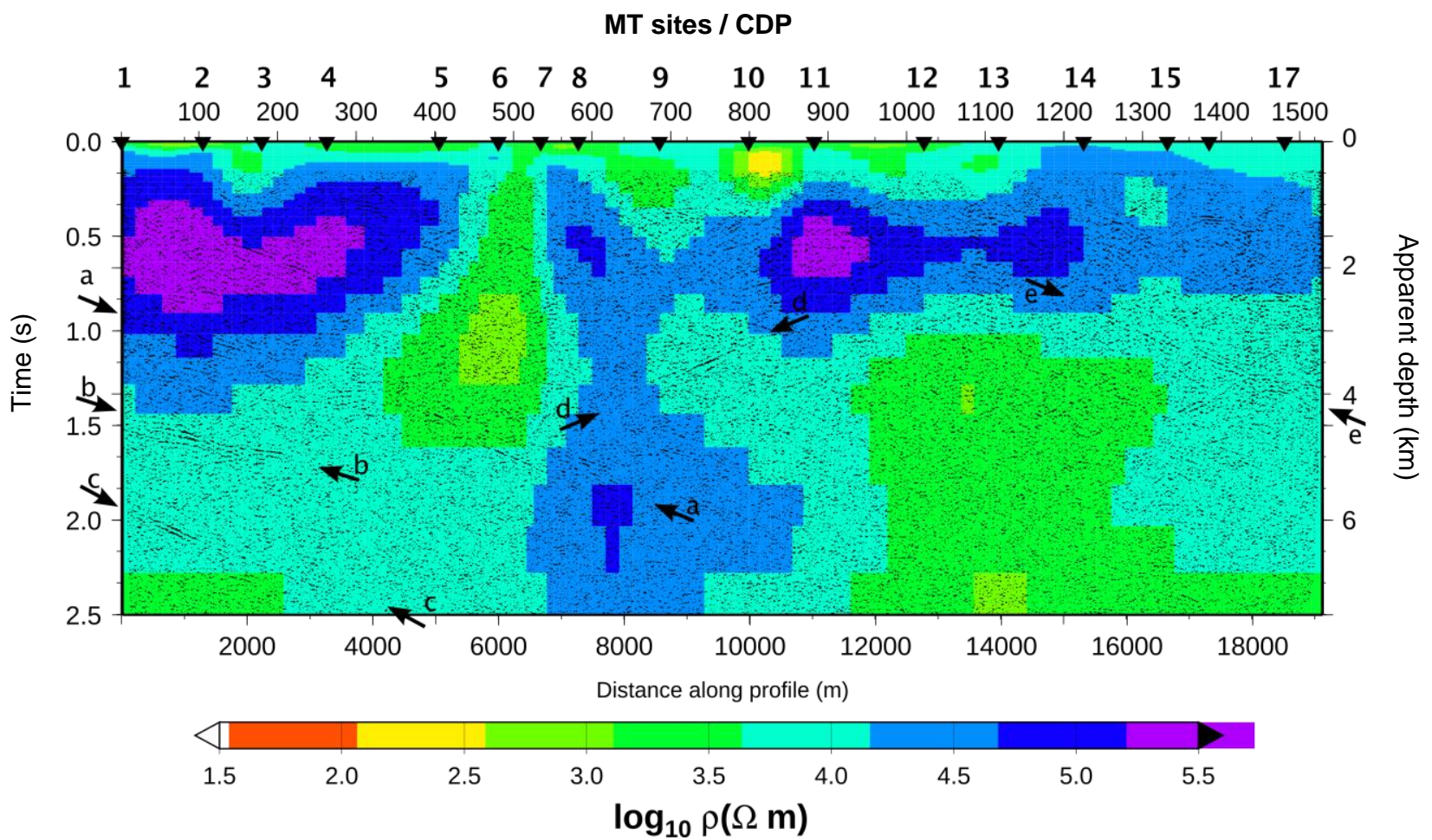

Figure 4. Seismic reflection stacked section with the upper part of the MT inversion model from Figure 3 as background. Note that the color scale is different from Figure 3. 


\section{EDITED REFERENCES}

Note: This reference list is a copy-edited version of the reference list submitted by the author. Reference lists for the 2011 SEG Technical Program Expanded Abstracts have been copy edited so that references provided with the online metadata for each paper will achieve a high degree of linking to cited sources that appear on the Web.

\section{REFERENCES}

Hübert, J., A. Malehmir, M. Smirnov, A. Tryggvason, and L. B. Pedersen, 2009, MT measurements in the western part of the Paleoproterozoic Skellefte Ore District, Northern Sweden: A contribution to an integrated geophysical study: Tectonophysics, 475, no. 3-4, 493-502, doi:10.1016/j.tecto.2009.06.011.

Malehmir, A., H. Thunehed, and A. Tryggvason, 2009, The Paleoproterozoic Kristineberg mining area, northern Sweden: Results from integrated 3D geophysical and geologic modeling, and implications for targeting ore deposits: Geophysics, 74, no. 1, B9-B22, doi:10.1190/1.3008053.

Pedersen, L. B., and M. Engels, 2005, Routine 2D inversion of magnetotelluric data using the determinant of the impedance tensor: Geophysics, 70, no. 2, G33-G41, doi:10.1190/1.1897032.

Rasmussen, T. M., Roberts, R. G., Pedersen, L. B., 1987, Magnetotellurics along the Fennoscandian Long-Range profile: Geophysical journal of the Astronomical Society, 89, 799-820.

Siripunvaraporn, W., and G. Egbert, 2000, An efficient data-subspace inversion method for 2D magnetotelluric data: Geophysics, 65, 791-803, doi:10.1190/1.1444778.

Tryggvason, A., A. Malehmir, J. Rodriguez-Tablante, C. Juhlin, and P. Weihed, 2006, Reflection seismic investigations in the western part of the paleoproterozoic VHMS-bearing Skellefte district, northern Sweden: Economic Geology and the Bulletin of the Society of Economic Geologists, 101, no. 5, 1039-1054, doi:10.2113/gsecongeo.101.5.1039. 